\title{
STRATEGIJSKO UPRAVLJANJE RESURSIMA PRIVREDNOG DRUŠTVA: KOMPARATIVNA ANALIZA SISTEMA ZA PLANIRANJE POSLOVNIH RESURSA (ERP) I RAČUNOVODSTVENIH INFORMACIONIH SISTEMA (RIS)
}

\author{
Maja Gligorić, \\ Tamara Kokić, \\ Ana Obradović, \\ Dušan Borovčanin
}

Univerzitet Singidunum, Beograd, Srbija

Odgovorno lice:

Maja Gligorić

e-pošta:

mgligoric@singidunum.ac.rs

\section{Rezime:}

Stalan i veoma brz razvoj informacionih i komunikacionih tehnologija, kao i turbulentno poslovno okruženje uslovile su promene u industrijskim granama. Od privrednih društava se zahteva stalno prilagođavanje i usavršavanje, jer samo ona koja su spremna za promene mogu biti označene kao konkurentne na tržištu rada. Sa druge strane, česta je situacija da privredna društva nestaju sa tržišta jer nisu sposobna da se menjaju ili prilagođavaju tržišnim uslovima. Međutim, visoki troškovi i poteškoće pri implementaciji poslovnih rešenja mogu itekako da utiču na dalji tok rada i uspešnost privrednog subjekta. U vezi sa tim, od privrednih društava očekuje se pažljiv odabir adekvatnog informacionog sistema uzimajući u obzir zahteve koje diktira njegovo poslovanje. Ovim radom je obuhvaćena komparativna analiza prednosti i nedostataka najzastupljenijih računovodstvenih informacionih sistema i sistema za planiranje poslovnih resursa na teritoriji Republike Srbije. Takođe, komparativnom analizom je definisana upotrebljivost informacionih sistema uzimajući u obzir veličinu privrednog društva.

Ključne reči:

računovodstveni informacioni sistemi, ERP rešenja, strategijsko upravljanje, informacione tehnologije, savremeno poslovno okruženje.

\section{UVOD}

Problem savremenog poslovanja privrednih društava, kako na teritoriji Republike Srbije tako i u drugim zemljama, je brza i česta promena trendova u poslovanju. U vezi sa tim, od privrednih društava zahteva se usvajanje specifičnih poslovnih modela, odnosno savremenih tehnika i metoda koje su fokusirane na dugoročni uspeh [1]. Globalizacija i takozvana nova ekonomija zasnivaju se na stalnim promenama i sve većoj upotrebi informacionih i komunikacionih tehnologija u poslovanju privrednih subjekata [2]. Tehnološka znanja i tehnički pronalasci promenili su poslovni ambijent, jer su pravovremenost i brzina osnovne karakteristike savremenog načina poslovanja. Važno je istaći da je računovodstveni informacioni sistem (skraćeno RIS) samo jedan od segmenata savremenog poslovnog sistema. Razvoj poslovanja privrednih društava u savremenom okruženju zasniva se na primeni različitih menadžment tehnika i softverskih rešenja koji utiču na razvoj konkurentnosti, fleksibilnosti, inovativnosti, kao i na unapređivanju znanja zaposlenih unutar 
privrednog društva, a posebno višeg rukovodstva [3]. U procesu planiranja i formulisanja strategije menadžment privrednog društva uvek polazi od raspoloživih resursa, uzimajući u obzir i resurse koje kompanija nedovoljno koristi. Na ovaj način obezbeđuje se efikasna i efektivna upotreba resursa privrednog društva i time se postiže pravovremeno reagovanje na promene u okruženju.

Kako bi privredna društva išla u korak sa vremenom, zadatak menadžmenta privrednog društva je implementacija određenog poslovnog rešenja ili sistema koji bi omogućio adekvatno upravljanje poslovnim procesima, odnosno što efikasnije korišćenje dostupnih resursa kompanije. Samim tim, korišćenjem nove tehnologije unutar privrednog društva menjaju se ciljevi i planovi kompanije, radne vrednosti, raspoloživi kadrovi, kao i sama organizaciona struktura društva. Brzo reagovanje u procesu donošenja poslovnih odluka predstavlja osnovni uslov za opstanak privrednog društva na tržištu rada. Ujedno, od samog menadžmenta privrednog društva zavisi da li su isti spremni za inovativna odlučivanja na osnovu kojih će društvu obezbediti bolju tržišnu poziciju [4].

\section{STRATEGIJSKO UPRAVLJANJE}

Strategijsko upravljanje predstavlja proces pomoću kojeg se donose i sprovode strategijske odluke koje omogućavaju privrednom društvu ostvarivanje željenog položaja na tržištu. Cilj strategijskog planiranja je da obezbedi sklad između sadašnje i planirane tržišne pozicije i načina dostizanja željenog cilja. Postoje dve faze u procesu strategijskog upravljanja, i to strategijsko planiranje i implementacija strategije. U prvoj fazi se vrši formulisanje same strategije poslovanja koja je orijentisana na tržišni rast i razvoj privrednog društva. Shodno tome, neophodna je spremnost menadžmenta za implementaciju i primenu informaciono-komunikacionih tehnologija. U drugoj fazi vrši se preduzimanje odgovarajućih akcija na osnovu tačno utvrđene strategije [5]. Menadžment privrednog društva, od koga zavisi inovativnost i rad same kompanije predstavlja najvažniju kariku u procesu uvođenja novih sistem pomoću kojih se vrši strategijsko upravljanje resursima privrednog društva. Zapravo, menadžment označava efektivno i efikasno upravljanje aktivnostima koje su vezane za posao koji ljudi treba da obave pojedinačno ili uz pomoć drugih ljudi [6].

\section{RAČUNOVODSTVENI INFORMACIONI SISTEM I SISTEM ZA PLANIRANJE POSLOVNIH RESURSA}

Razvoj i primena informaciono-komunikacionih tehnologija uslovile su nastanak savremenog poslovnog ambijenta. Primena elektronskog poslovanja je iz korena promenila način poslovanja, te je postalo neophodno redefinisanje poslovnih procesa unutar poslovnih sistema, a u skladu sa njima i informacionih potreba. Računovodstveni informacioni sistemi predstavljaju formalne procedure kojima se vrši prikupljanje podataka, koje se zatim obrađuju u informacije, i kao takve se dostavljaju korisnicima. Osnovni uslov za rad i opstanak privrednog društva na tržištu predstavlja efikasno korišćenje računovodstvenog informacionog sistema. Međutim, ukoliko privredna društva za cilj imaju automatizaciju i integraciju poslovnih aktivnosti i poslovnih procesa unutar društva neophodno je korišćenje integrisanog poslovnog rešenja, odnosno Enterprise Resource Planning (ERP). Osnovni cilj primene integrisanog poslovnog rešenja je pomoć privrednom društvu u uštedi resursa, ali i u efikasnosti poslovanja [7].

\section{RAČUNOVODSTVENI INFORMACIONI SISTEMI}

Uspešno poslovanje privrednih društava obuhvata adekvatnu primenu i upotrebu računovodstvenih informacionih sistemi koji direktno utiču na obradu finansijskih i nefinansijskih transakcija unutar istog. Implementacija i upotreba računovodstvenih informacionih sistema predstavlja neophodan segment savremenog poslovanja za privredna društva, koji dodatno pojednostavljuje svakodnevne poslovne transakcije. U daljem tekstu predstavićemo prednosti i nedostatke računovodstvenih informacionih sistema koji su najzastupljeniji na teritoriji Republike Srbije.

\section{Lidder MRS}

Privredno društvo New Dimension osnovano je 1992. godine sa idejom razvoja i kreiranja adekvatnog softverskog rešenja. Lidder predstavlja monolitni računovodstveni softver koji omogućava efikasan rad korišćenjem raznovrsnih i jednostavnih softverskih alata. Računovodstveni softver Lidder prevashodno je namenjen malim i srednjim privrednim društvima koja posluju u dinamičnom okruženju sa većim brojem 
komitenata. Računovodstveni servisi koriste Lidder u cilju vođenja dvojnog knjigovodstva, u proseku za oko 30 malih ili srednjih privrednih društava po jednom serveru. Najveću funkcionalnost postiže primenom u privrednim društvima koja generišu oko 10.000 dokumenata i 10.000 artikala godišnje i rade sa oko 1000 aktivnih komitenata.

Računovodstveni softver Lidder prilagođen je korisnicima različitih obima poslovanja i sastoji se od sledećih tehničkih verzija:

- ENT je ENTerprise verzija Liddera;

- PRO je PROfessional verzija Liddera;

- STD je STanDard verzija Liddera;

- START je STanDard verzija Liddera koja ne može imati terminale;

- EDUCA je START verzija Liddera koja je besplatna, ali sa nekim dodatnim ograničenjima.

Benefit korišćenja ovog savremenog softverskog rešenja ogleda se u mogućnosti sveobuhvatnog vođenja knjigovodstva i knjiženja svih poslovnih promena uključujući i računovodstveno planiranje i analizu, računovodstvenu kontrolu i reviziju koja se zasniva na poštovanju računovodstvene teorije i prakse [8].

\section{Mali poslovni program 2 - MPP2}

Mali poslovni program 2 (u daljem tekstu MPP2) predstavlja savremeni računovodstveni softver koji omogućava sveobuhvatnu evidenciju poslovnih transakcija, nadzor i kontrolu poslovanja privrednih subjekata. MPP2 je druga generacija računovodstvenog softvera organizacije Privredni Savetnik, zastupljen na tržištu Republike Srbije od 2010. godine. Korisnici imaju mogućnost da se opredele za pojedinačne segmente koji su im neophodni za svakodnevno obavljanje poslovnih aktivnosti. MPP2 poseduje osnovni, standardni i napredni nivo funkcionalnosti, sastoji se od 11 softverskih modula koji se odnose na različite segmente poslovanja. Navedeni nivoi pružaju mogućnost korišćenja određenih funkcija softvera. Osnovni nivo omogućava funkcije koje su potrebne malim privrednim društvima u svakodnevnom poslovanju. Standardni nivo predstavlja unapređenu verziju funkcija osnovnog nivoa, dok napredni nivo pruža kompletno izveštavanje i kontrolu celokupnog poslovanja [9].

\section{SISTEMI ZA PLANIRANJE POSLOVNIH RESURSA (ENTERPRISE RESOURCE PLANNING)}

Sistemi za planiranje poslovnih resursa spajaju i obrađuju informacije koje su zasnovane na praćenju procesa unutar privrednog društva, na osnovu čega se postiže potpuna upotrebljivost raspoloživih resursa privrednog društva. S obzirom da sistemi za planiranje poslovnih resursa predstavljaju veoma kompleksna i skupa rešenja za vođenje poslovanja, u daljem tekstu predstavićemo njihove prednosti i nedostatke.

\section{SAP}

SAP je svetski lider, odnosno treći najveći nezavisni proizvođač softvera na svetu u poslovnim aplikacijama po kriterijumu prihoda od softvera i usluga vezanih uz softver. Takođe, kompanija SAP predstavlja najveće evropsko softversko privredno društvo čiji programi olakšavaju strategijsko upravljanje resursima kompanije i nude sistem za planiranje poslovnih procesa (Enterprise Resource Planning - u daljem tekstu ERP). Kompanija SAP je na tržištu započela kao proizvođač ERP softvera, a danas predstavlja vodeću kompaniju za ponudu ERP rešenja. SAP ERP rešenje koristi se od strane 50.000 korisnika širom sveta, koji podržava procese u 25 industrijskih grana, u upotrebi je na čak 37 jezika i u 45 lokalizovanih varijanti [10].

Sistem za planiranje poslovnih resursa, odnosno $\boldsymbol{E R P}$ rešenje je softverski paket koji predstavlja skup alata i procesa za upravljanje poslovnim aktivnostima. Spomenuti sistemi omogućavaju kompanijama trenutno reagovanje na tržišne promene zahvaljujući razvrstavanju podataka, poslovnih objekata i procesa kojima se upravlja u realnom vremenu [11]. ERP sistemi su postali veoma važni za procese poslovanja kompanija širom sveta, jer su im omogućili da pojednostave svoje poslovanje, kao i da iskoriste i integrišu proces poslovnih podataka. ERP rešenja su razvijena kako bi ispunila poslovne zahteve kompanije u celini, i kao takva u sebi sadrže iskustvo i veštine preuzete iz kompanija, kao i od prethodnih korisnika. Takođe, da bi kompanije uspešno implementirale ERP projekte, neophodno je da izaberu ERP sistem koji može biti usklađen sa potrebama kompanije [12]. Osnovna i najvažnija karakteristika ERP sistema je integrisano planiranje i kontrola svih značajnih resursa posmatranog poslovnog sistema. Odnosno, pomenuti sistem omogućava povezivanje svih delova 
(sektora) poslovanja u jedan jedinstveni integrisani sistem, pomoću kojeg se odvija stalna komunikacija, kao i deljenje informacija iz iste baze podataka. ERP sistem omogućava jednostavnije obavljanje poslova uz smanjenje papirologije i povećanje produktivnosti [13].

Jako je važno napomenuti da kompanija SAP nudi softverska rešenja za privredna društva svih veličina. $U$ vezi sa tim, SAP Business Suite predstavlja integrisanu poslovnu aplikaciju koja se koristi u različitim industrijskim granama, za privredna društva koja zapošljavaju od 100 do 500 radnika. Sa druge strane, osnovna ponuda kompanije SAP sastoji se od SAP Business All-in-One i SAP Business One poslovnog softvera. Poslovno rešenje SAP Business All-in-One namenjen je malim i srednjim privrednim društvima koje zapošljavaju do 2.500 radnika, dok je SAP Business One kreiran za mala privredna društva koja zapošljavaju manje od 100 radnika [14], [10].

\section{Pantheon}

Razvoj novih tehnologija uslovio je korišćenje informacionih sistema za uspešno upravljanje privrednim društvima. Još jedan predstavnik ERP poslovno-informacionih sistema je Pantheon, kreiran od strane kompanije Datalab. Privredno društvo Datalab osnovano je 1997. godine sa sedištem u Sloveniji i trenutno broji 56.089 prodatih licenci. Pantheon je pre svega namenjen privrednim društvima koja ostvaruju brz rast i razvoj na tržištu i povećava funkcionalnost i stabilnost kompletnog poslovnog sistema. U fokusu njihovog poslovanja je kreiranje odgovarajućih informacionih sistema za vođenje malih, srednjih i velikih privrednih društava. Sistem je prilagođen za rad zaposlenih u okviru različitih sektora (rukovodstvo, računovodstvo, nabavka, prodaja itd.). Stoga, Datalab je razvio nekoliko Pantheon softverskih sistema za unapređenje poslovanja, i to: Pantheon - Small Business, Pantheon - Enterprise, Pantheon - Accounting, Pantheon - Retail, Pantheon - Manufacture, Pantheon Public service, Pantheon - Specific Solutions [15].

\section{PREDNOSTI SISTEMAZA PLANIRANJE POSLOVNIH RESURSA I RAČUNOVODSTVENIH INFORMACIONIH SISTEMA}

U tabeli br. 1 biće predstavljena komparativna analiza prednosti sistema za planiranje poslovnih resursa i računovodstvenih informacionih sistema [8], [9], [10], [15].

Tabela 1. Komparativna analiza prednosti sistema za planiranje poslovnih resursa i računovodstvenih informacionih sistema

\section{PREDNOSTI SISTEMA ZA PLANIRANJE} POSLOVNIH RESURSA

SAP PANTHEON

» Povećava konkurentnost pomoću brzih, integrisanih i pre svega fleksibilnih procesa

» Modernizuje poslovne procese

» Ušteda vremena potrebna za lansiranje na tržište

» Obezbeđivanje mobilne, Cloud i inmemory tehnologije

» Kontrola kvaliteta

» Razvoj proizvoda i procesa proizvodnje

» Unapređenje poslovnih procesa

» Smanjenje zaliha gotovih proizvoda, poluproizvoda i nedovršene proizvodnje
Prilagođava se potrebama klijenata

» Unapređenje poslovnih procesa

» Objedinjuje administraciju i operativne procedure

» Minimiziranje nastanka grešaka

» Izuzetno visok povraćaj na investiciju

» Kompletna integrisana mrežna rešenja

» Povećanje produktivnosti

» Poboljšana komunikacija i razmena informacija sa stejkholderima
PREDNOSTI RAČUNOVODSTVENIH INFORMACIONIH SISTEMA

\section{LIDDER}

"Cena softvera

» Jednostavna implementacija

» Nivo/obim podrške

» Jednostavna upotreba

» Efikasnost i brzina početka rada

» Obuhvatnost kompletnog poslovanja privrednog društva

» Usklađenost sa zakonskim propisima

» Profesionalni alat za vođenje poslovanja koji radi uvek nezavisno od interneta

» Koristi uvedenog sistema su vidljive $u$ kraćem vremenskom periodu
» Usklađenost sa zakonskim propisima

» Fleksibilnost i otvorenost

» Modularnost

» Elektronska komunikacija

» Korišćenje i tehnička podrška

» Mogućnost preuzimanja podataka iz drugog softvera

» Koristi uvedenog sistema su vidljive $u$ kraćem vremenskom periodu 
7. NEDOSTACI SISTEMAZA PLANIRARANJE POSLOVNIH RESURSA I RAČUNOVODSTVENIH INFORMACIONIH SISTEMA

Pogrešno je razmišljanje menadžmenta privrednog društva da će uvođenje određenog informacionog rešenja u poslovni sistem preko noći poboljšati poslovne procese privrednog društva. Međutim, od odabira određenog sistema zavisi kako će se isti uklopiti sa strategijom, poslovnom kulturom i strukturom privrednog društva. U vezi sa tim, u daljem tekstu navedeni su osnovni nedostaci informacionih sistema [8], [9], [10], [15]:

- Visoka cena softvera;

- Visoki troškovi infrastrukture;

- Visoki troškovi uvođenja i implementacije softvera;

- Visoki troškovi za integraciju i testiranje;

- Visoki troškovi i obimna obuka kadrova;

- Visoki troškovi održavanja sistema;

- Teška integracija sa ostalim poslovnim rešenjima;

- Reorganizacija postojećih poslovnih aktivnosti i procesa;

- Veliki broj softverskih rešenja ne radi ukoliko nema internet konekcije;

- Ugrožena bezbednost podataka;

- Često javljanje grešaka;

- Koristi uvedenog sistema nisu odmah vidljive.

Svako privredno društvo ima svojstven način poslovanja na tržištu rada, pa u vezi sa tim svaki pojedinačni privredni sistem ima različite zahteve od svog informacionog sistema. Uvođenjem pogodnog računovodstvenog ili ERP sistema rukovodstvo privrednog društva može uticati na unapređenje svojih performansi, tržišne konkurentnosti i uspešnosti poslovanja [16]. Za privredno društvo je itekako važno uvođenje sveobuhvatnog i jedinstvenog informacionog sistema, jer od istog zavisi poslovanje privrednog društva. Od veličine i obima poslovanja privrednog subjekta zavisi izbor odgovarajućeg softverskog rešenja. U skladu sa pomenutim, privredna društva moraju jasno da definišu potrebna rešenja za svoju organizaciju, jer na primer ERP sistemi imaju veliki broj modula čije dodavanje može uticati na povećanje angažovanja i troškova. Da bi privredno društvo uvelo i implementiralo određeni informacioni sistem potrebna je adekvatna infrastruktura koja iziskuje visoke troškove. Za uspešno uvođenje sistema neophodna je stručna podrška prilikom projektovanja, odnosno dizajna projekta implementacije, programiranja, nadzora, obuke korisnika za rad, kao i njegovog kasnijeg održavanja [17]. Implementacija računovodstvenog informacionog sistema ili ERP rešenja zahteva detaljno finansijsko planiranje, kao i izradu budžeta, koja je relativno dugog trajanja. Konsalting predstavlja sastavnu savetodavnu uslugu u procesu uvođenja i implementacije određenog sistema od strane eksternih stručnjaka softverske kuće koje uglavnom svoje usluge naplaćuju po radnom satu. Osnovni problem sa kojim se menadžment privrednog društva često susreće su koristi uvedenog sistema koje nisu odmah vidljive, već je potrebno vreme za prilagođavanje konkretnim potrebama društva.

\section{ZAKLJUČNA RAZMATRANJA}

Tehničko - tehnološki razvoj i globalizacija uslovili su promenu rada u svakodnevnom poslovanju privrednih društava. U savremenom društvu korišćenje informacionih tehnologija omogućava izvršenje radnih procesa brže, efikasnije i kvalitetnije. Privredno društvo koje poseduje adekvatne resurse, nastoji da iste sačuva i unapredi. Da bi se pomenuto postiglo, u organizaciji moraju postojati određene strategije za razvoj istih. Zadatak menadžmenta privrednog društva je da motiviše zaposlene u procesu ispunjenja zajedničkih ciljeva i vrednosti. Takođe, od menadžera se zahteva i donošenje poslovnih odluka na osnovu pravovremenih $\mathrm{i}$ tačnih informacija. U savremenim uslovima rada, privredna društva na raspolaganju imaju veliki broj alata za operativno i strategijsko upravljanje. Jedan od alata za strategijsko upravljanje resursima društva predstavljaju računovodstveni informacioni sistemi i ERP rešenja koja se koriste za optimizaciju i automatizaciju poslovnih procesa, a koji su neophodni za postizanje ciljeva privrednog društva.

$\mathrm{Na}$ osnovu izvršene komparativne analize najzastupljenijih softverskih rešenja na teritoriji Republike Srbije definisani su informacioni sistemi koji imaju veću/manju upotrebljivost u privrednim društvima. $\mathrm{U}$ zavisnosti od veličine privrednog društva, koja je uslovljena brojem zaposlenih, imovinom, ostvarenim rezultatom poslovanja, određuje se vrsta informacionog sistema koji će se implementirati unutar poslovnog sistema. $U$ vezi sa tim, pomenuta softverska rešenja poput Lidder-a i MPP2 koriste se za mikro, mala i srednja privredna društva zbog ograničenih funkcionalnih mogućnosti. Sa druge strane, softversko rešenje SAP i Pantheon predstavljaju sisteme koji omogućavaju sveobuhvatno planiranje poslovnih resursa posebno kreirane za srednje i velike poslovne 
sisteme. Komparativnom analizom ustanovljeno je da su benefiti primene računovodstvenih informacionih sistema i ERP rešenja daleko značajnija u odnosu na njihove nedostatke. Glavni problem implementacije i uvođenja novog softverskog rešenja predstavljaju visoki početni troškovi, koji se mogu kvantitativno izraziti. Takođe, problem predstavljaju i koristi uvedenog sistema koje nisu odmah kvantitativno i kvalitativno merljive. Međutim, nakon određenog perioda adaptacije i prilagođavanja uvedenog softverskog rešenja potrebama privrednog društva postiže se efikasnija i efektivnija upotreba postojećih i neiskorišćenih resursa. Samim tim, izvršene promene poboljšaće buduće poslovanje kroz procese planiranja, dostizanje kratkoročnih i dugoročnih planova, kao i buduće investicije privrednog društva.

\section{ZAHVALNOST}

Rad je deo projekta "Organizaciona i informaciona podrška sistemu upravljanja kvalitetom kao ključni faktor u povećanju konkurentnosti naših kompanija i njihovom bržem ulasku na svetsko i EU tržište", br. 179001, u vremenskom trajanju od 2011-2019, finansiran iz sredstava Ministarstva prosvete, nauke i tehnološkog razvoja Republike Srbije.

\section{LITERATURA}

[1] Đervida, R., Radosavac, A., \& Rodić, V. (2016). KARAKTERISTIKE SAVREMENOG POSLOVANJA. Poslovne studije, 2016, 15-16, 363-373.

[2] Gabrić, M., \& Jakovac, P. (2016). GLOBALIZACIJSKI PROCESI I BUDUĆA FAZA RAZVOJA KAPITALIZMA. Časopis za ekonomiju i politiku tranzicije , 1-18.

[3] Bešić, C., \& Đorđević , D. (2008). RAZVOJ KORPORATIVNOG PREDUZETNIŠTVA KAO PREDUSLOVA ZA UNAPREĐIVANJE KONKURENTNOSTI PREDUZEĆA. Tranziicija 10(21-22), 101-110.

[4] Pettigrew, A. (2001). THE POLITICS OF ORGANIZATIONAL DECISION-MAKING. London: Tavistock Publications Limited .
[5] Delibašić, D. (2018). Specijalistički rad: Strategijsko upravljanje i konkurentska prednost. 1-60. Beograd: Strategijski Menadžment I Related PDF's.

[6] Albijanić, M. (2013). Strategijski menadžment. Beograd: Univerzitet Singidunum.

[7] Petrović, Z., Knežević, G., \& Milojević, M. (2016). Računovodstveni informacioni sistemi. Beograd: Univerzitet Singidunum.

[8] Lidder. (2019). Retrieved from http://lidder.nd.rs/

[9] Privredni Savetnik Informacione Tehnologije. (2019). Retrieved from https://www.mpp2.rs/

[10] SAP. (2018). Retrieved from https://www.sap.com/

[11] Wei, C.-C., Chien, C.-F., \& Wang, M. (2005). An AHP-based approach to ERP system selection Author links open overlay panel. International Journal of Production Economics, Volume 96, Issue 1, 4762.

[12] Karsak, E., \& Ozogul, O. (2009). An integrated decision making approach for ERP system selection. Expert Systems with Applications, 660-667.

[13] Beheshti, H. M. (2006). What managers should know about ERP/ERP II. MANAGEMENT RESEARCH NEWS, 184-193.

[14] Tomić, Ž. (2016). INTEGRACIJA MODELA ZA UPRAVLJANJE RESURSIMA PREDUZEĆA I ODNOSIMA S POTROŠAČIMA U INFORMACIONO-TEHNOLOŠKOJ DELATNOSTI. 1-188. Beograd: Fakultet za poslovne studije, Beograd .

[15] Datalab. (2019). PANTHEON. Retrieved 2 1, 2019, from https://www.datalab.rs/ [15] Beheshti, H. M. (2006). What managers should know about ERP/ERP II. MANAGEMENT RESEARCH NEWS, 184-193.

[16] Zykov, S. (2018). Enterprise Resource Planning Systems: the Integrated Approach. Proceedings of the 3d International Workshop on Computer Science and Information Technologies (pp. 284-295). Ithaca: Cornell University Library.

[17] Nović, N. (2018). Master rad: ERP- Istorijat razvoja, polje pirmene i novi oblici poslovanja primenom cloud rešenja. Beograd: Univerzitet Singidunum. 